\title{
Neural migration disorders studied by cerebral ultrasound and colour Doppler flow imaging
}

\author{
Adelina Pellicer, Fernando Cabañas, Antonio Pérez-Higueras, Alfredo García-Alix, \\ José Quero
}

\begin{abstract}
Cerebral ultrasound and colour Doppler flow imaging (CDFI) were used to diagnose a wide spectrum of anomalies of cell migration (17 patients): presumed lissencephaly $(n=12)$; schizencephaly of both fused $(n=2)$ and open lips $(n=2)$; hemimegalencephaly $(n=1)$; and subependymal type grey matter heterotopia $(n=12)$. The patients with grey matter heterotopia had irregular ventricular margins $(n=10)$, periventricular hyperechogenic bands $(n=12)$, and/or periventricular hyperechogenic nodules $(n=7)$. Some patients had more than one type of migration disorder as well as other central nervous system malformations. Cerebral ultrasound diagnoses were confirmed by magnetic resonance imaging (MRI) or necropsy.

It is concluded that colour Doppler flow imaging is a worthwhile addition to the assessment of brain surface anomalies.
\end{abstract}

(Arch Dis Child 1995; 73: F51-F61)

Keywords: cerebral ultrasound, neuroblast migration disorders, schizencephaly, colour Doppler flow imaging.

Disturbances in the early migration of neuroblasts are rare but usually important causes of neurological impairment, such as motor, learning, and behavioural disorders, and epilepsy. The early recognition of neuroblast migration disorders (MD) is important. First, to establish the prognosis of future neurological abnormalities. Second, to make a correct syndromic diagnosis, because $\mathrm{MD}$ are an essential feature of chromosomal or genetic syndromes that have a particular rate of recurrence. ${ }^{1-3}$

Early disorders of neural cell migration produce several types of dysgenetic cerebral outcomes: agyria-pachygyria complex (lissencephaly), polymicrogyria, schizencephaly, unilateral megaloencephaly, and grey matter heterotopia. ${ }^{4}$ Often, more than one is found in the same brain.

Our understanding of such disorders has been greatly enhanced by the use of high resolution magnetic resonance imaging (MRI) ${ }^{4-9}$ There have been few reports on neural migration disorders diagnosed using cerebral ultrasound, ${ }^{10-16}$ most reporting some aspect of the different dysgenetic changes that characterise such anomalies.

This paper aims to highlight the usefulness of cerebral ultrasound and colour Doppler flow imaging (CDFI) in the diagnosis of these disorders by describing a full spectrum of neural migration disorders that have been fully identified using this non-invasive method.

\section{Methods}

From January 1991 to December 1993, 6337 cerebral ultrasound scans were performed on 2659 patients in our neonatal division, either during their hospital stay or after discharge. This study focuses on 17 patients who presented with different types of developmental brain anomalies which were studied by cerebral ultrasound and CDFI. The patients' mean birthweights and gestational ages were $2.5 \mathrm{~kg}$ (range 1.9-2.8) and 37.3 weeks (range 33-39), respectively (table). In seven patients (cases $1-3,7,11,14$, and 16) intrauterine ultrasonography suggested central nervous system (CNS) malformation. In the other 10 patients the cerebral ultrasound studies were made for abnormalities detected in the neonatal period: lumbar myelomeningocele (case 12), macroencephalia (cases 4, 5, and 17), dysmorphic syndrome (cases 6, 8, 9, and 13), forceps injury (case 10), and abnormal neurological assessment (case 15).

Real time sector scans were made using a Toshiba SSH-140 A CDFI system fitted with a $5 \mathrm{MHz}$ probe. The brain was examined on several axes of the coronal, sagittal, and parasagittal planes, through the anterior fontanelle. To evaluate the brain surface, the transducer was angled (tangential plane): in the coronal plane it was angled towards the frontal and occipital brain surface, and in the sagittal planes, towards both hemispheric convexities.

CDFI studies were used to examine the abnormalities of brain surface vascular pattern, especially in those patients with ultrasonographic signs of cortical dysgenesis. All cerebral ultrasound scans were performed by the same researchers (AP and FC), and recorded on videotape.

Unenhanced axial computed tomography (CT) scans were obtained in eight patients 


\begin{tabular}{|c|c|c|c|c|c|c|c|c|c|c|}
\hline \multirow{4}{*}{$\begin{array}{l}\text { Case } \\
\text { No }\end{array}$} & \multirow{4}{*}{$\begin{array}{l}\text { Gestational } \\
\text { age (week) } \\
\text { Birth } \\
\text { weight }(\mathrm{kg})\end{array}$} & \multicolumn{7}{|c|}{ Neuronal migration disorcers } & \multirow{4}{*}{$\begin{array}{l}\text { Others } \\
\text { (cerebral ultrasound } \\
\text { and/or MRI) }\end{array}$} & \multirow[b]{4}{*}{ Other main diagnosis } \\
\hline & & \multicolumn{6}{|c|}{ Cerebral ultrasound } & \multirow{3}{*}{$\begin{array}{l}\text { Magnetic resonance } \\
\text { imaging }\end{array}$} & & \\
\hline & & \multirow{2}{*}{$\begin{array}{l}\text { Agyrial } \\
\text { pachygyria }\end{array}$} & \multirow[b]{2}{*}{ Schizencephaly } & \multicolumn{3}{|c|}{$\begin{array}{l}\text { Grey matter } \\
\text { heterotopia } \\
\end{array}$} & \multirow{2}{*}{$\begin{array}{l}\text { Unilateral } \\
\text { megaloencephaly }\end{array}$} & & & \\
\hline & & & & $I V M$ & $B$ & $N$ & & & & \\
\hline 1 & $\begin{array}{l}34 \\
2 \cdot 2\end{array}$ & + & Fused lips & + & + & + & & $\begin{array}{l}\text { Pachygyria, fused lips } \\
\text { schizencephaly, PV grey } \\
\text { matter heterotopia (thin } \\
\text { layer and focal avoid } \\
\text { nodules) }\end{array}$ & $\begin{array}{l}\text { Dysgenesia CC, } \\
\text { colpocephaly, Dandy- } \\
\text { Walker malformation }\end{array}$ & $\begin{array}{l}\text { Hydrocephalus, hyaline } \\
\text { membrane disease }\end{array}$ \\
\hline 2 & $\begin{array}{l}36 \\
2 \cdot 8\end{array}$ & & & + & + & + & & $\begin{array}{l}\text { PV grey matter heterotopia } \\
\text { (thin layer) }\end{array}$ & $\begin{array}{r}\text { Dysgenesia CC, } \\
\text { encephalocele }\end{array}$ & $\begin{array}{l}\text { Occipital encephalocele, } \\
\text { hydrocephalus, } \\
\text { coanae atresia }\end{array}$ \\
\hline 3 & $\begin{array}{l}39 \\
2 \cdot 7\end{array}$ & & & + & + & + & & $\begin{array}{l}\text { PV grey matter heterotopia } \\
\text { (thin layer) }\end{array}$ & $\begin{array}{l}\text { Dysgenesia CC, Chiari } \\
\text { malformation }\end{array}$ & $\begin{array}{l}\text { Lumbar } \\
\text { myelomeningocele }\end{array}$ \\
\hline 4 & $\begin{array}{l}33 \\
2 \cdot 2\end{array}$ & + & & & & & & $\begin{array}{l}\text { Frontal agyria, parietal- } \\
\text { occipital pachygyria }\end{array}$ & SE-IVH & $\begin{array}{l}\text { Undefined dysmorphic } \\
\text { syndrome }\end{array}$ \\
\hline 5 & $\begin{array}{l}37 \\
3 \cdot 2\end{array}$ & + & & + & + & & & $\begin{array}{l}\text { Pachygyria, grey matter } \\
\text { heterotopia (thin layer) }\end{array}$ & $\begin{array}{l}\text { HTBG. Absent frontal } \\
\text { interventricular septum. }\end{array}$ & $\begin{array}{l}\text { Undefined dysmorphic } \\
\text { syndrome }\end{array}$ \\
\hline 6 & $\begin{array}{l}36 \\
2 \cdot 7\end{array}$ & + & & + & + & & & $\begin{array}{c}\text { Pachygyria, grey matter } \\
\text { heterotopia (thin layer) }\end{array}$ & $\begin{array}{l}\text { Dysgenesia CC, } \\
\text { colpocephaly, cerebellar } \\
\text { hypoplasia. HTBG }\end{array}$ & $\begin{array}{l}\text { Smith-Lemli-Opitz } \\
\text { syndrome }\end{array}$ \\
\hline 7 & $\begin{array}{l}38 \\
1 \cdot 9\end{array}$ & + & & & & & & Pachygyria & $\begin{array}{l}\text { Ventriculomegaly, } \\
\text { calcifications cerebral } \\
\text { atrophy, HTBG }\end{array}$ & $\begin{array}{l}\text { Congenital CMV } \\
\text { infection }\end{array}$ \\
\hline 8 & $\begin{array}{l}37 \\
2 \cdot 2\end{array}$ & + & & + & + & + & & & $\begin{array}{l}\text { Dysgenesia CC, cerebellar } \\
\text { hypoplasia }\end{array}$ & $\begin{array}{l}\text { Walker-Warburg } \\
\text { syndrome }\end{array}$ \\
\hline 9 & $\begin{array}{l}40 \\
1.9\end{array}$ & & & & + & & & $\begin{array}{l}\text { Grey matter heterotopia } \\
\text { (thin layer) }\end{array}$ & HTBG & Fetal alcohol syndrome \\
\hline 10 & $\begin{array}{l}35 \\
2 \cdot 8\end{array}$ & & & + & + & + & & $\begin{array}{l}\text { Grey matter heterotopia } \\
\text { (thin layer and ovoid focal } \\
\text { nodules) }\end{array}$ & Megacisterna & $\begin{array}{l}\text { Hyaline membrane } \\
\text { disease }\end{array}$ \\
\hline 11 & $\begin{array}{l}39 \\
2 \cdot 2\end{array}$ & + & & + & + & + & + & $\begin{array}{l}\text { Right sided megalencephaly, } \\
\text { right temporal-occipital } \\
\text { pachygyria, right PV grey } \\
\text { matter heterotopia (thin } \\
\text { layer and focal ovoid } \\
\text { nodules) }\end{array}$ & & \\
\hline 12 & $\begin{array}{l}39 \\
2 \cdot 4\end{array}$ & & & + & + & & & $\begin{array}{l}\text { PV grey matter heterotopia } \\
\text { (thin layer) }\end{array}$ & Chiari malformation & $\begin{array}{l}\text { Lumbar } \\
\text { myelomeningocele }\end{array}$ \\
\hline 13 & $\begin{array}{l}40 \\
2 \cdot 4\end{array}$ & + & & & & & & Pachygyria (mainly frontal) & Cerebellar hypoplasia & $\begin{array}{l}\text { Cornelia de Lange } \\
\text { syndrome }\end{array}$ \\
\hline 14 & $\begin{array}{l}38 \\
3 \cdot 2\end{array}$ & + & & & + & & & $\begin{array}{l}\text { Agyria, PV grey matter } \\
\text { heterotopia (thin layer) }\end{array}$ & $\begin{array}{l}\text { Dysgenesia CC and } \\
\text { mesencephalon, } \\
\text { ventriculomegaly, Dandy } \\
\text { Walker malformation }\end{array}$ & $\begin{array}{l}\text { Walker-Warburg } \\
\text { syndrome }\end{array}$ \\
\hline 15 & $\begin{array}{l}39 \\
2 \cdot 9\end{array}$ & + & Open lips & & & & & $\begin{array}{l}\text { Open lips schizencephaly, } \\
\text { pachygyria }\end{array}$ & $\begin{array}{l}\text { Dysgenesia CC, } \\
\text { colpocephaly }\end{array}$ & \\
\hline 16 & $\begin{array}{l}38 \\
3 \cdot 3\end{array}$ & + & $\begin{array}{l}\text { Open and } \\
\text { fused lips }\end{array}$ & + & + & + & & $\begin{array}{l}\text { Parieto-temoral-occipital } \\
\text { pachygiria PV grey matter } \\
\text { heterotopia (thin layer and } \\
\text { focal ovoid nodules), open } \\
\text { and fused lips } \\
\text { schizencephaly }\end{array}$ & $\begin{array}{l}\text { Dysgenesia CC, } \\
\text { colpocephaly }\end{array}$ & \\
\hline 17 & $\begin{array}{l}36 \\
2 \cdot 5\end{array}$ & + & & & & & & Generalised pachygyria & $\begin{array}{l}\text { Hydrocephalus, dysgenesia } \\
\text { CC PV calcifications, } \\
\text { multicystic } \\
\text { encephalomalacia, } \\
\text { HTBG }\end{array}$ & $\begin{array}{l}\text { Congenital toxoplasma } \\
\text { infection }\end{array}$ \\
\hline
\end{tabular}

IVM=irregular ventricular margin; $B=$ band; $N=$ nodule; $C C=$ corpus callosum; SE-IVH=subependymal intraventricular haemorrhage; $H T B G=$ hyperechogenic areas in thalamus and basal ganglia; $\mathrm{CMV}=$ cytomegalovirus; $\mathrm{PV}=$ periventricular.

(cases 1, 4-7, 10, 14, and 15) using a high resolution technique on continuous $5 \mathrm{~mm}$ thick slices.

All patients in the study except case 8 had an MRI scan. The studies were obtained with MRI equipment operating at $0.5 \mathrm{~T}$, with $5 \mathrm{~mm}$ thick slices spaced every $2 \mathrm{~mm}$. Spin-echo pulse sequences were performed. $\mathrm{T} 1$ weighted $450 / 25$, T2 weighted $2000 / 100$, and proton density weighted 2000/35 MRI scans were obtained.

For computed tomography and MRI studies, patients were sedated with chloral hydrate and monitored by pulse oxymetry and/or cardiorespiratory monitoring during the procedure. All computed tomography and MRI scans were reviewed by one of the authors (AP-H), who was unaware of the cerebral ultrasound diagnosis and clinical condition of the patients. MD and other brain anomalies were diagnosed on the basis of MRI findings. In case
8, an infant who died in the neonatal period, the brain was also studied histologically.

\section{Results}

CEREBRAL ULTRASOUND FINDINGS

Abnormal gyral development

Lissencephaly was suggested by the presence of a smooth surfaced brain with poor sulci (fig 1B) and rudimentary sylvian fissures as an expression of absent or incomplete operculation, and absence of sulcation on the interhemispheric face in the coronal planes. Cases $1,4-8,11,13-17$ showed these characteristic findings to a variable degree (table). Using CDFI, we identified the middle cerebral artery in the sylvian fissure, in both the coronal and sagittal planes. In these patients the vessel showed a straight course without the normal branching pattern (figs 1A, B). The sulcal arteries on the brain surface were scanty and 


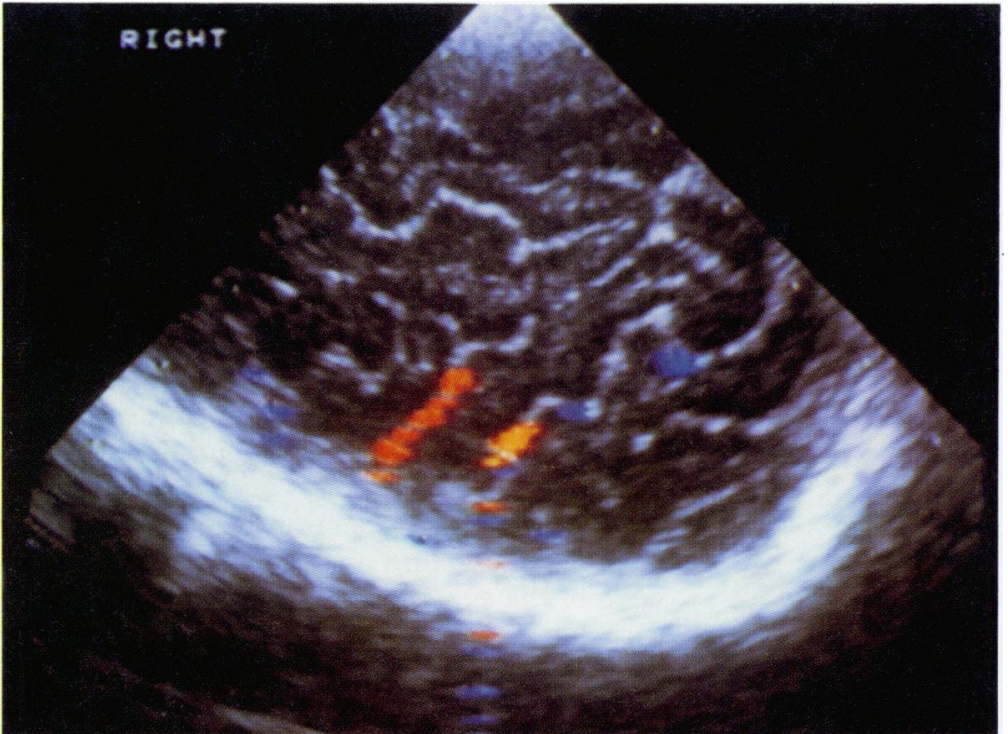

Fig $1 A$

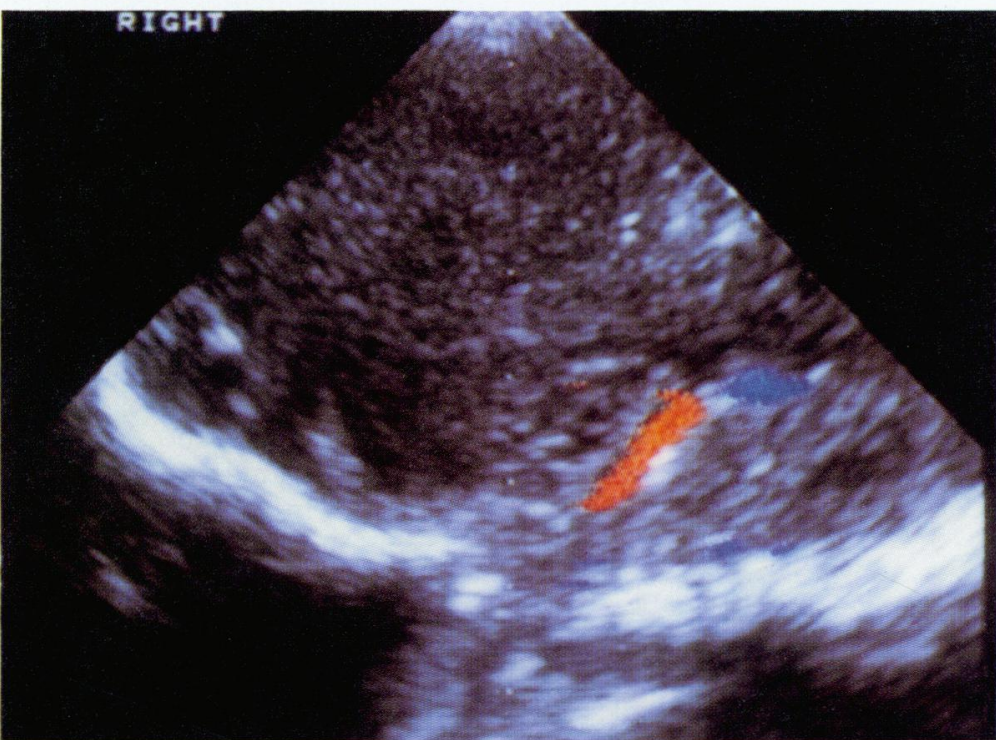

Fig $1 B$

Figure 1 (A) Sagittal sonogram showing a normal brain surface and its vascularisation. (B) Same view in a patient with lissencephalia (case 17). Note smooth surfaced brain with poor sulci. Cerebral vasculature is abnormally reduced.

did not show the normal sinuosity in patients with poor sulcation (figs $1 \mathrm{~A}, \mathrm{~B}$ ).

Grey matter heterotopia of subependymal type Three findings were considered to be primary cerebral ultrasound changes suggestive of grey matter heterotopia of the subependymal type. First, irregular ventricles - that is, an irregular outer contour of the lateral ventricles (figs $3 \mathrm{~A}$ and 4A). Second, a periventricular band, defined as a hyperechogenic (different from the adjacent periventricular white matter but less echogenic than the choroid plexus) ribbon, either continuous or discontinuous, and present in the periventricular region (figs $3 \mathrm{~A}$ and $4 \mathrm{~A}$ ). And third, a periventricular nodule, when the above mentioned hyperechogenicity had a rounded (or ovoid) appearance, occurred alone or as multiple nodules, and was located close to the ventricular wall, sometimes protruding into the ventricular lumen (fig $3 \mathrm{~A}$ ).
The table lists the patients in our series with such cerebral ultrasound findings (cases 1-3, $5,6,8-12,14$, and 16 ). Ten out of 12 patients had irregular ventricular margins and seven had bands and nodules as well.

\section{Schizencephaly}

Schizencephaly was suspected when there were breaks along the ventricular wall and in communication between the ventricular lumen and subarachnoid space. This cerebral ultrasound finding was identified as a cleft. Two patients (cases 1 and 16) did not have open communication between these two compartments, so a fused lips schizencephaly was suspected (fig 5A). We also had two cases of open lips schizencephaly (cases 15 and 16). Case 15 had a wide defect; case 16 had a narrow cleft in the occipital horn of the right ventricle (fig $6 \mathrm{~A}$ ).

\section{Unilateral megaloencephaly}

Unilateral megaloencephaly was considered when there was an interhemispheric asymmetry - that is, the presence of an unilaterally enlarged hemisphere with ipsilateral ventriculomegaly and shifting of the interhemispheric fissure, falx, and superior sagittal sinus to the opposite side (case 11).

\section{OTHER TECHNIQUES}

In all cases MRI confirmed the diagnoses of either $M D$ or other associated dysgenetic findings suggested by cerebral ultrasound (figs $3 \mathrm{~B}, 4 \mathrm{~B}, 5 \mathrm{C}$, and $6 \mathrm{~B}$ ) (table). With respect to cortical dysgenesis, the anomalies of the brain surface could be clearly visualised using this technique (table).

Subependymal heterotopias appeared as isointense nodular masses of cortical grey matter of different size and distribution. Very small nodules formed a thin layer of heterotopic grey matter that completely or partially surrounded the lateral ventricles when distributed continuously (fig 4B). Larger, single, or multiple masses of grey matter heterotopia were typified as void focal nodules (table) (fig 3B).

In eight out of 17 patient computed tomography studies were also performed. There was a good correlation between computed tomography and MRI findings in all cases of cortical dysgenesis and/or schizencephaly (fig 5B), but computed tomography scans were not diagnostic of grey matter heterotopia in two patients (cases 5 and 10). MRI and computed tomography scans failed to indicate hyperechogenic areas detected by cerebral ultrasound in the thalamus and basal ganglia (table).

Histopathological evaluation of the brain of case 8 revealed dysgenesis of the corpus callosum and colpocephaly, generalised pachygyria without clear laminar stratification (type II lissencephaly), gross grey matter heterotopia in the subependymal and centrum semiovale regions, and a hypoplastic postero-inferior cerebellar vermix. 


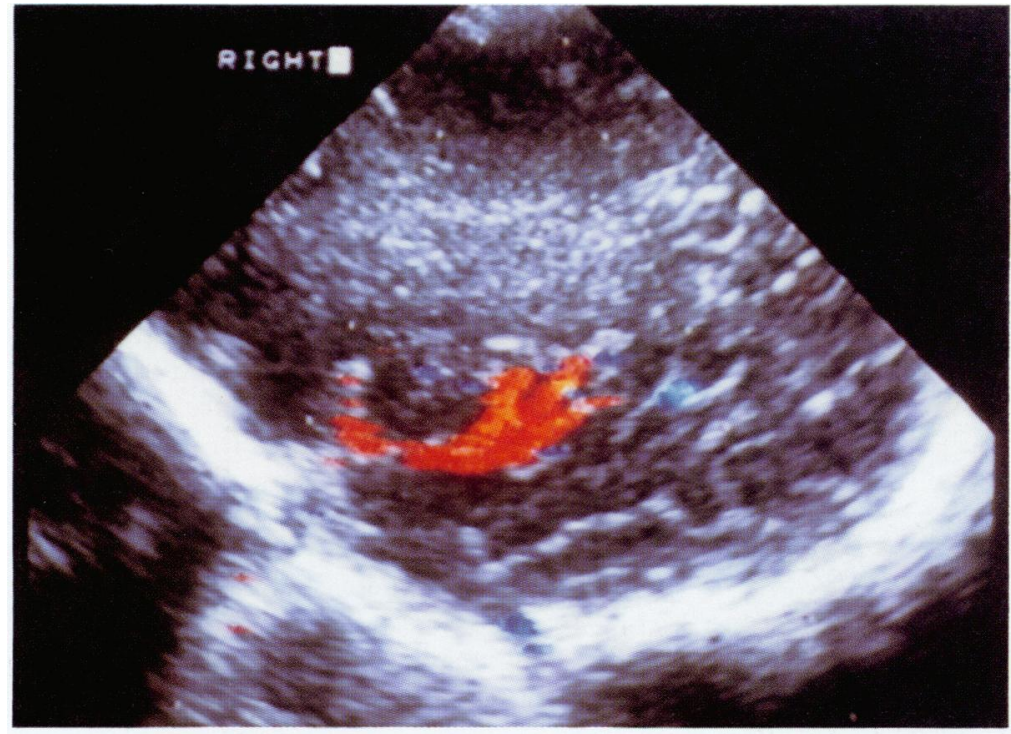

Fig $2 A$

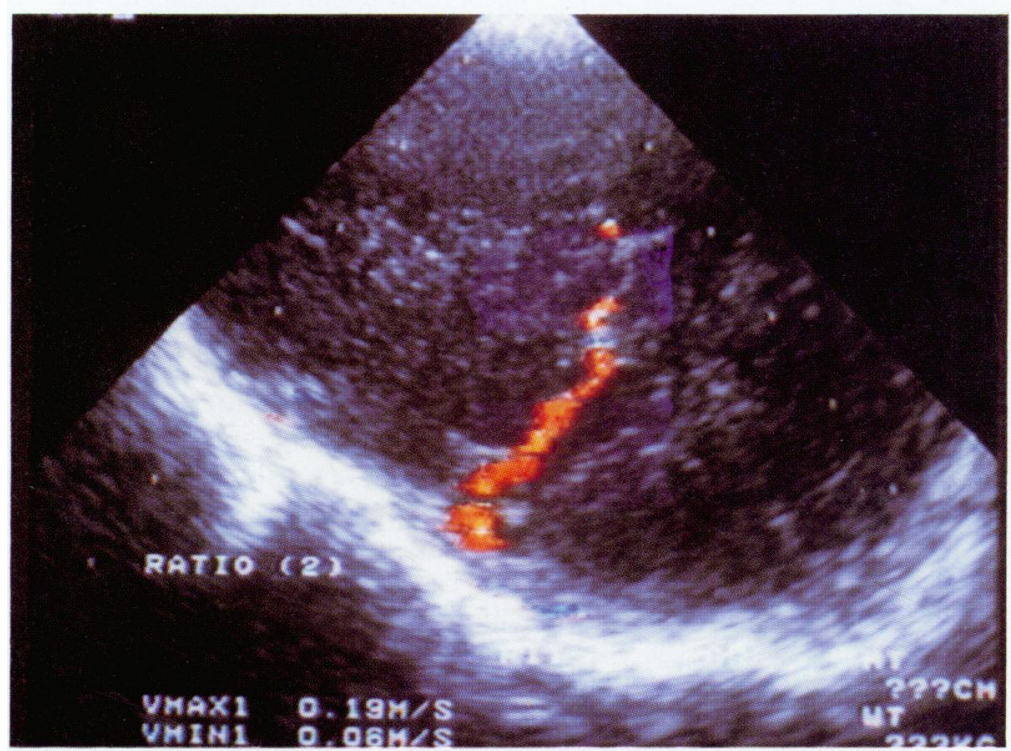

Fig $2 B$

Figure 2 (A) Parasagittal sonogram displaying brain cortex and the middle cerebral artery branching at the level of the sylvian fissure. (B) Sonogram illustrating a poor brain surface sulcation and middle cerebral artery in the sylvian fissure that is straight and without divisions (case 6). techniques to diagnose them is probably limited.

As far as we know, the value of cerebral ultrasound for diagnosing MD has not been evaluated completely, although some dysgenetic changes characterising such anomalies have already been described as lissencephaly, 101314 open lips schizencephaly (fig 7),111215 or hemimegalencephaly. ${ }^{16}$ This is the first description of the cerebral ultrasound findings of a full spectrum of early $\mathrm{MD}$ in a series of patients. This is important because ultrasonography is the main neuroimaging tool in the neonatal period.

The grey matter heterotopias diagnosed by cerebral ultrasound in this group of patients were of the subependymal type. ${ }^{6}$ Nevertheless, their distribution was not consistently symmetrical or bilateral, and band patterns outnumbered nodular patterns in our series. We do not think that this is a new pattern of grey matter heterotopia but, as previously reported, ${ }^{19}$ that subependymal heterotopias form nodular masses ranging in diameter from 1 $\mathrm{mm}$ to $20 \mathrm{~mm}$. A continuous distribution of smaller nodular masses along the subependymal zone could produce a band image on sonograms. This interpretation is supported by MRI findings ${ }^{20}$ in which the heterotopia appears as small nodules suggesting a thin layer of grey matter lining the ventricles (fig 4). Likewise, the irregular ventricular margins are probably the consequence of such nodular displacement and were a consistent finding in these patients except in two cases. In case 9 the ventricular space was almost obliterated and its shape could not be discerned. In contrast, in case 14 the ventricular walls were distended by high intracranial pressure (obstructive hydrocephalus). Alleviation of intracranial pressure might have revealed an irregular ventricular contour. Couture et al suggest that the modification of the ventricular margin should evoke the presence of periventricular grey matter heterotopia. ${ }^{13}$

Although grey matter heterotopias are congenital anomalies to be expected in a child with severe dysmorphic features, 41719 they may also be present in patients with otherwise 'minor' CNS malformations. It may be that when these grey matter heterotopias are not diffuse and the normal cortical gyral pattern is conserved, as was the case in some of our patients (table), the disruption of the migration process is less severe. ${ }^{7}$ These patients may be almost normal in early childhood, and only later sustain onset of uncontrolled seizures.

Another interesting finding of our study is the diagnosis of fused lips squizencephaly in two patients using cerebral ultrasound. Although computed tomography showed the defect in one patient (case 1), axial computed tomography scans may not identify such anomalies. ${ }^{4}$ Thus theoretically, cerebral ultrasound should be better for the diagnosis of small, narrow clefts because different planes can be obtained. Our two cases diagnosed by cerebral ultrasound provide further support for this.

Although the resolution of cerebral ultrasound is remarkable, MRI is still needed of subsequent neurological dysfunction, is unknown, and the ability of routine imaging 


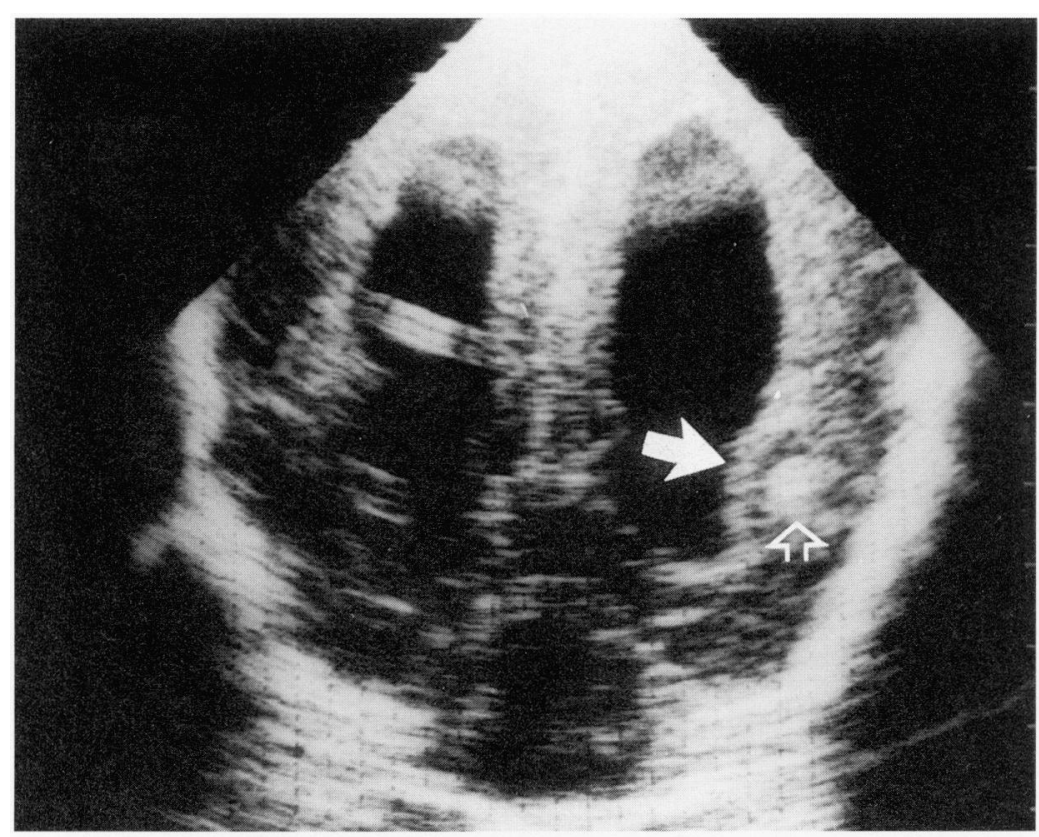

Fig $3 A$

Figure 3 (A) Cerebral ultrasound scan showing bilateral ventriculomegaly of irregular margins in a coronal plane, a periventricular band (arrow), and a periventricular nodule (open arrow) (case 1). (B) T1 weighted MRI scan of an axial plane. Heterotopic grey matter surrounding the lateral ventricles (arrows). and a periventricular ovoid mass of grey matter (open arrow) protruding into the ventricular lumen.

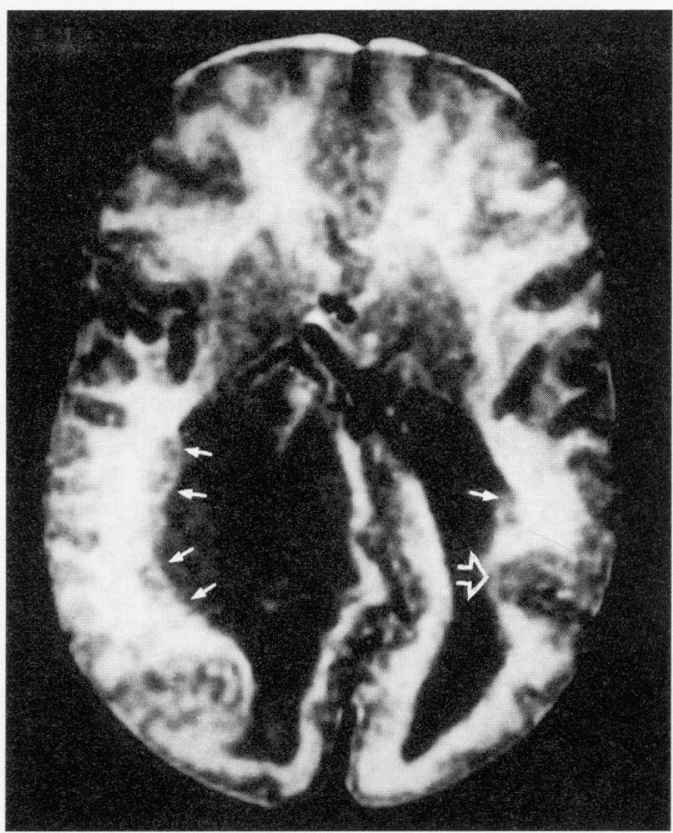

Fig $4 A$ (Below)

Fig $3 B$

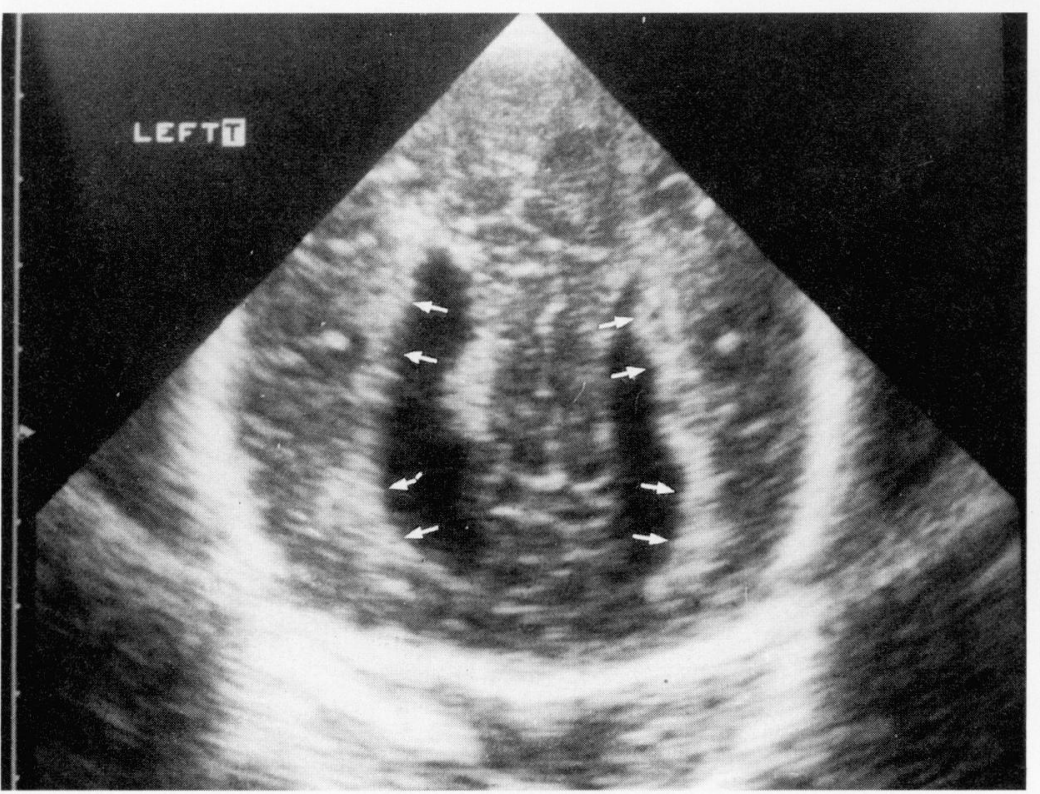

because it is the best technique for differentiating grey from white matter. ${ }^{6}$ Sonography was not able to characterise the cortical surface precisely. Although we use the term 'lissencephalic brains', cortical anomalies could be clearly classified by MRI or histology only as agyria-pachygyria complex or polymicrogyria. Computed tomography scans are also limited in the diagnosis of polymicrogyria, possibly because of beam-hardening artefacts created by the bone. ${ }^{4}$ Nevertheless, cerebral ultrasound is valuable for detecting brain surface anomalies when patients are mature enough, and so the diagnosis of lissencephaly has been made by cerebral ultrasound at 33 weeks of gestational age. ${ }^{10}$ We performed serial cerebral ultrasound in all the patients. The earliest diagnosis of altered gyral development was made in a patient at 33 weeks' postconceptional age and confirmed in the cerebral ultrasound sequential evaluation. High frequency probes (10 $\mathrm{MHz}$ ) were used to evaluate cortical-subcortical brain damage after hypoxia-ischaemia ${ }^{21} 22$ and to identify changes in the brain surface suggestive of altered gyral development. ${ }^{13}$ These transducers make it possible to show the brain surface in the projections usually included in routine cerebral ultrasound evaluation. Nevertheless, to visualise the brain surface we used tangential planes and added CDFI to identify both the gyri and the vessels. Murphy et $a l^{23}$ also using a $5 \mathrm{MHz}$ probe, studied similar tangential planes to evaluate gyral development, and created a scoring system. The combination of cerebral ultrasound and CDFI clearly shows abnormal vascular patterns of the middle cerebral artery in the sylvian fissure and of the sulcal arteries on the brain surface (figs 1 and 2). Thus we found CDFI to be very useful

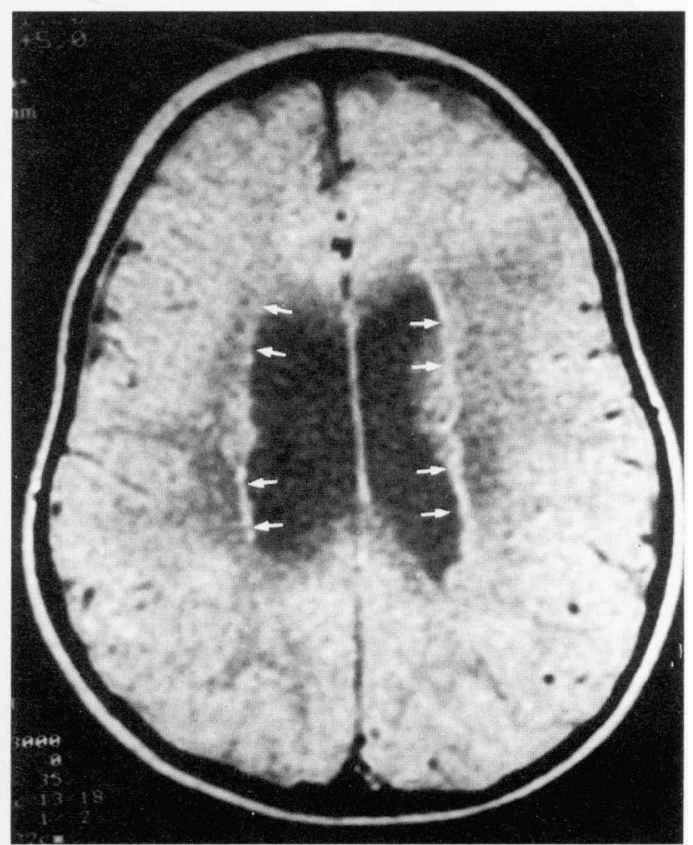

Fig $4 B$ (Above)

Figure 4 (A) Coronal plane cerebral ultrasound scan showing both sides of a periventricular band (arrows) (case 10). (B) Proton density weighted MRI scan of the same patient showing a thin layer of heterotopic grey matter lining the ventricular walls (arrows). 


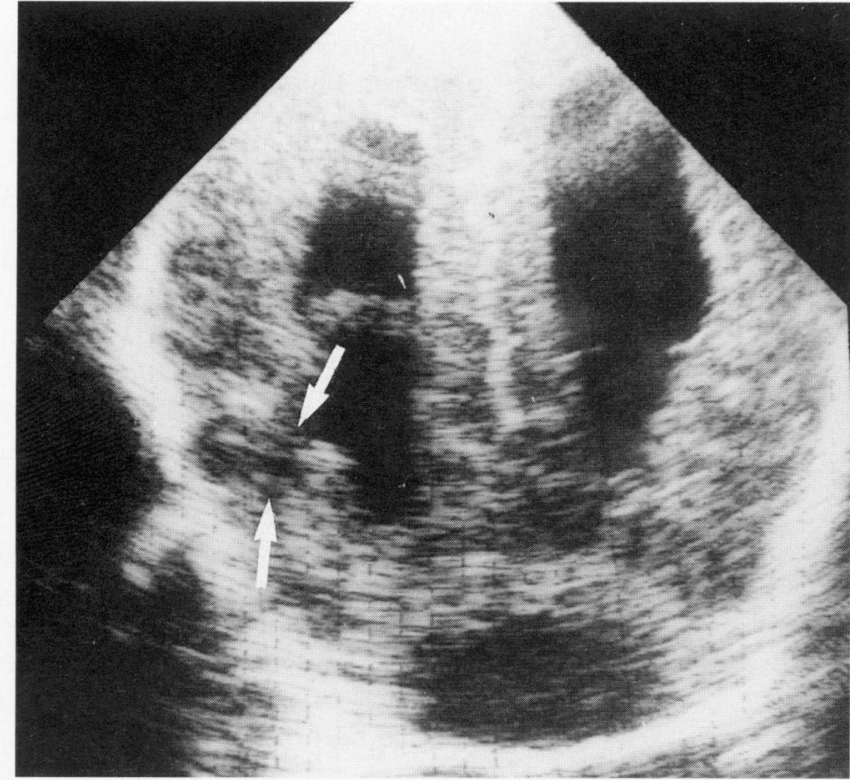

Fig 5 A

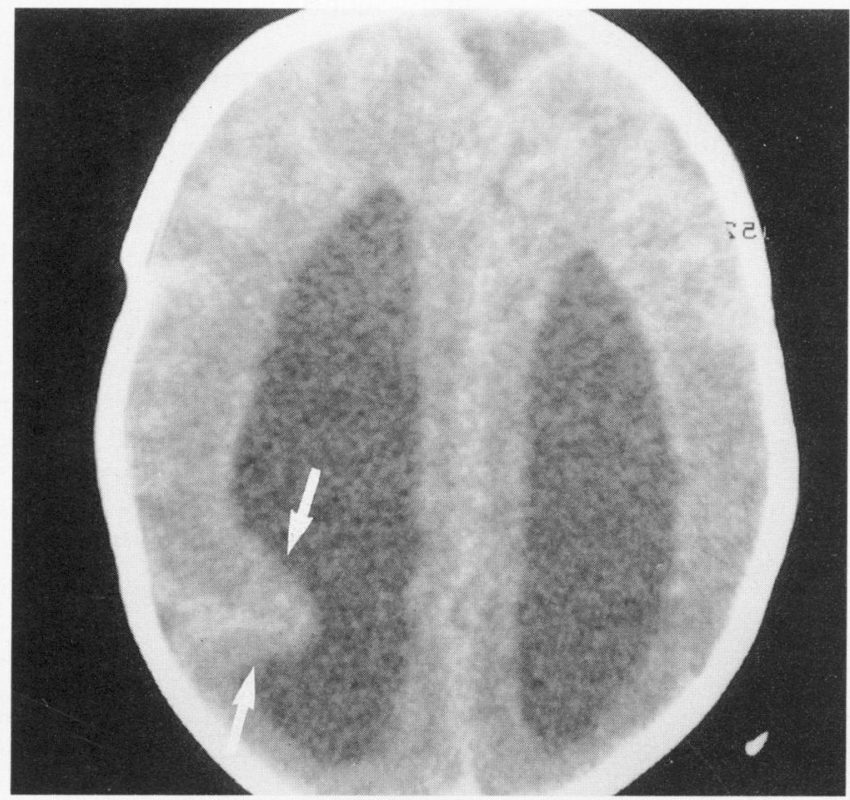

Fig $5 B$

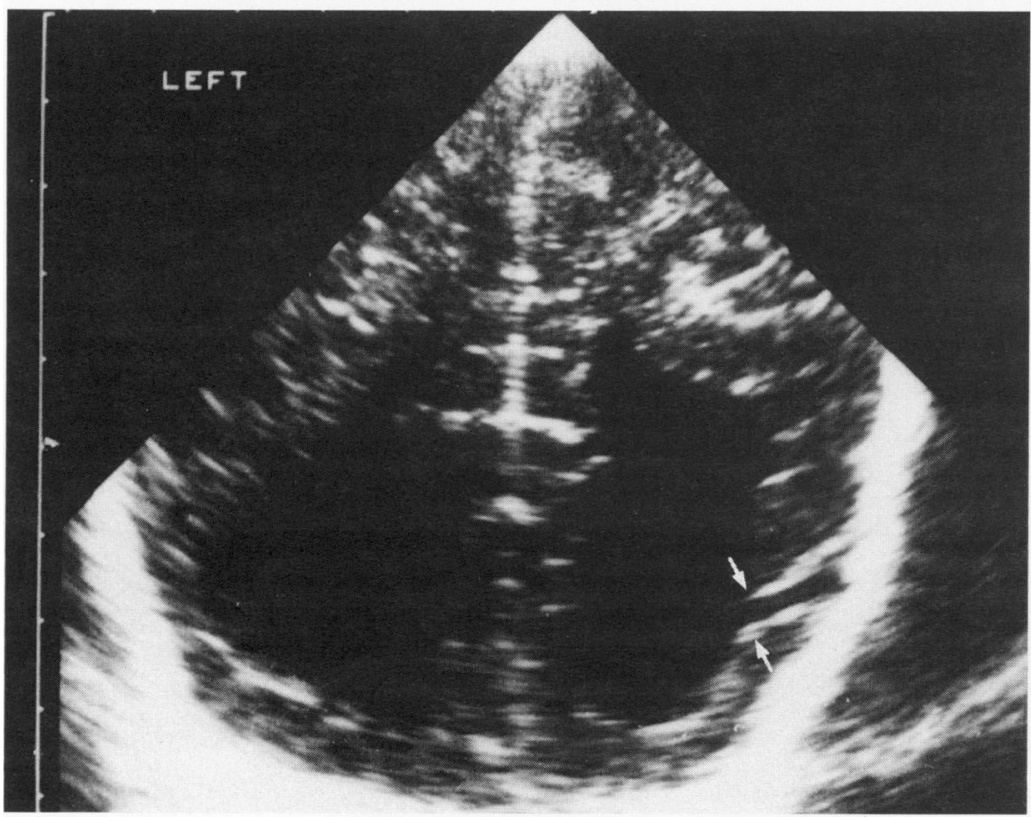

Fig 6 A

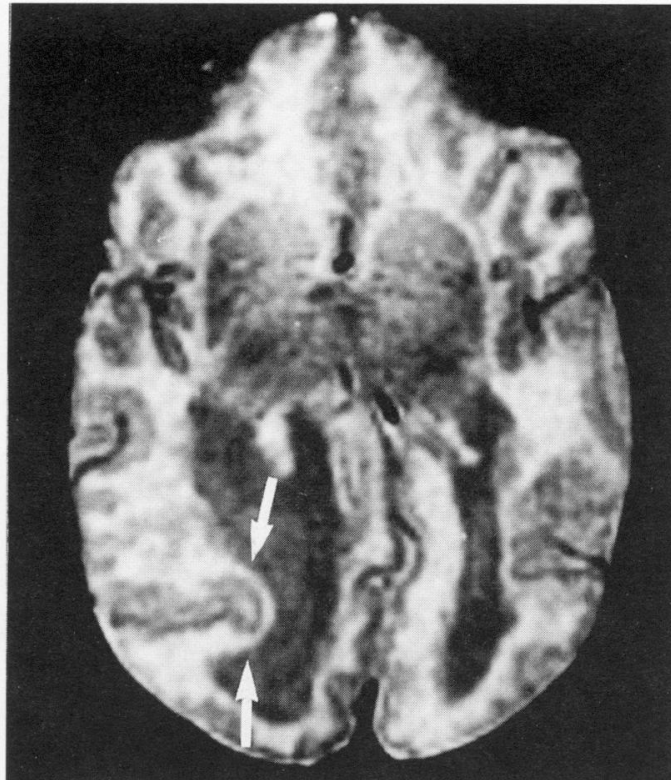

Fig $5 C$

Figure 5 (A) Coronal plane ultrasound scan of case 1, who presented with a cystic malformation of the posterior fossa and a hypoechoic area extending from the bone and through the left hemisphere with no communication with the ventricle (arrows), as well as a hyperechogenic, almost horizontal band inside the hypoechoic zone. (B) Axial computed tomography scan representing the fused lips schyzencephalia (arrows) (C) The same view with T1 weighted MRI confirms the cerebral ultrasound and computed tomography findings (arrows).

addition to the assessment of cortical configuration.

We found that cerebral ultrasound and MRI 67911 were better diagnostic tools for grey matter heterotopias than computed tomography especially for small, focal lesions. On the other hand, neither MRI nor computed tomography recognised hyperechogenic areas

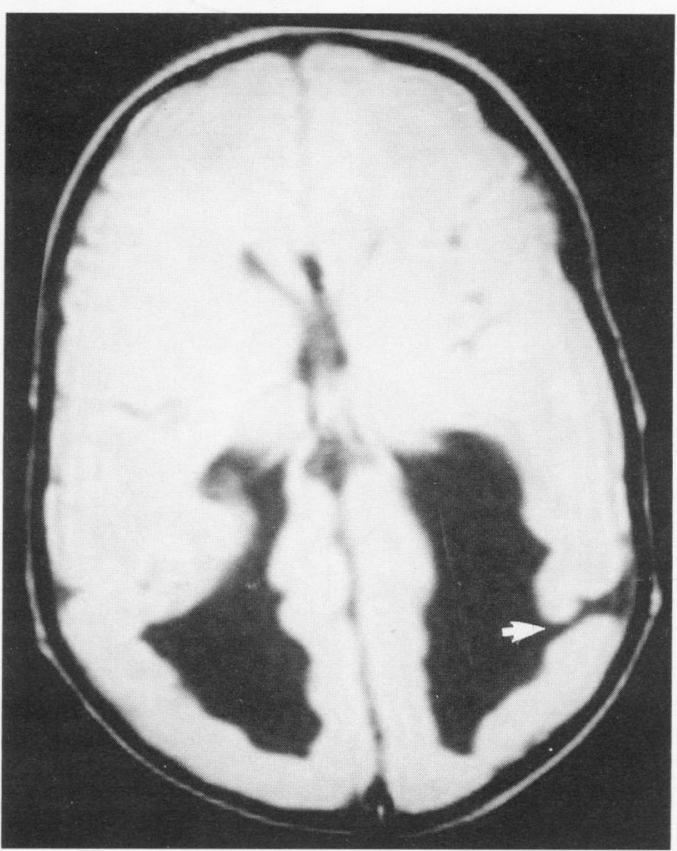

Fig $6 B$

Figure 6 (A) Coronal plane sonogram at parietal-occipital level, depicting open lips schyzencephalia (arrows) (case 16). (B) Proton density MRI scan of axial plane confirming the cleft (arrow).

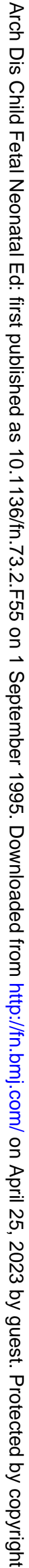




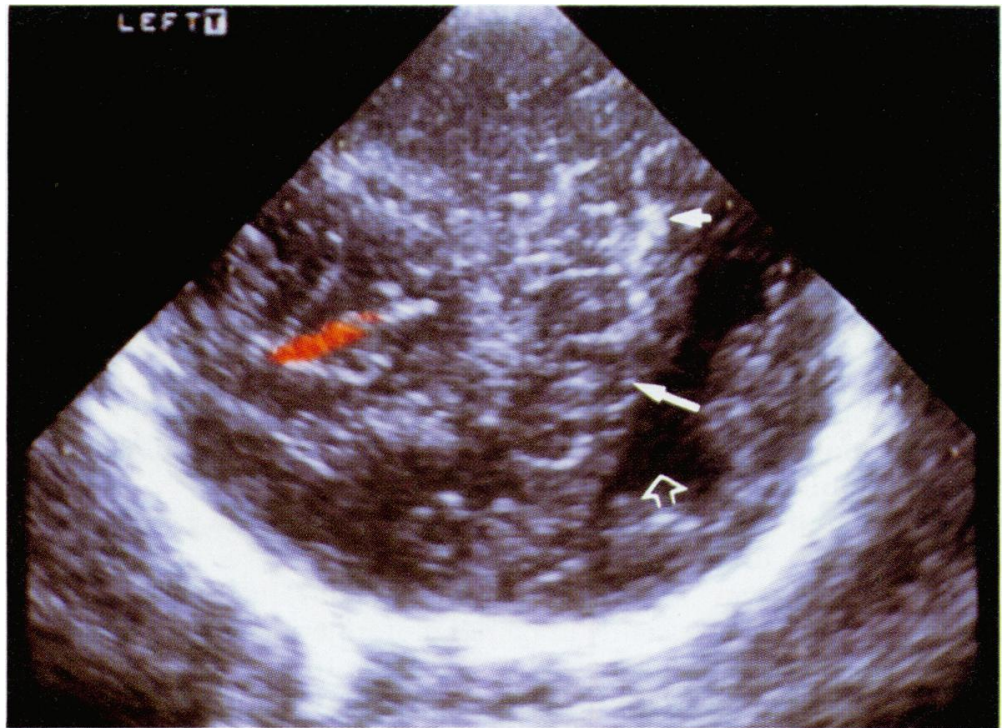

Figure 7 Open lips schizencephalia surrounded by abnormal cortex and CDFI.

detected by cerebral ultrasound in the thalamus and basal ganglia (table), as has been reported before. ${ }^{24}$

The association of $\mathrm{MD}$ with other dysgenetic brain anomalies in this series was noteworthy. Barkovich et al also noted that the observation of isolated dysgenesis of the corpus callosum is rare and that patients with this anomaly usually are symptomatic, suggesting the presence of other associated congenital brain anomalies. ${ }^{25}$ Thus as the index of suspicion rises and more imaging studies are done, a larger number of grey matter heterotopias and/or other types of $\mathrm{MD}$ patterns will appear. It is to be expected that the spectrum of neuroimaging abnormalities will correlate with the clinical evolution of these patients. ${ }^{20}$

Finally, we can conclude that, although this study was not designed to assess the value of cerebral ultrasound for diagnosing $\mathrm{MD}$, our results show that certain sonographic findings are suggestive of $\mathrm{MD}$ and may be diagnostic of some types.

In summary, cerebral ultrasound is a good method for screening for $\mathrm{MD}$. Tangential planes allow cortical gyral development to be assessed. CDFI improves the sensitivity of cerebral ultrasound by showing abnormalities in the brain surface vascular pattern in cases of abnormal sulcation. Although subependymal grey matter heterotopia usually accompany more complex dysgenetic cerebral disorders, and thus are an indicator of their presence, they may also occur as isolated malformations with an unpredictable prognosis, so these patients must be followed up. In any case when cerebral ultrasound findings are suggestive of $M D$, a full MRI study should be done.

This study was presented, in part, at the 4th European Workshop on Neonatology, Corfu, Greece, October, 1993.

1 Dobyns WB, Stratton RF, Greenberg F. Syndromes with lissencephaly. I: Miller-Dieker and Norman-Roberts syndromes and isolated lissencephaly. Am $₹$ Med Genet 1984; 18: 509-26.

2 Dobyns WB, Kirkpatrick JB, Hittner HM, Roberts RM, Kretzer FL. Syndromes with lissencephaly. II: WalkerWarburg and cerebro- and oculo-muscular syndromes and a new syndrome with type II lissencephaly. Am f Med Genet 1985; 22: 157-95.

3 Miller GM, Stears JC, Guggenheim MA, Wilkening GN. Schizencephaly: a clinical and CT study. Neuroradiology 1984; 34: 997-1001.

4 Barkovich AJ, Chuang SH, Norman D. MR of neuronal migration anomalies. $A m$ f Radiol 1988; 150: 179-87.

5 Aicardi J. The lissencephaly syndromes. Int $\mathcal{f}$ Pediatr 1989; 4: 118-26.

6 Barkovich AJ, Jackson DE, Boyer RS. Band heterotopias: A newly recognized neuronal migration anomaly. Radiology 1989; 171: 445-8.

7 Palmini A, Andermann F, de Grissac H, Tampieri D, Robitaille Y, Langevin P, et al. Stages and patterns of centrifugal arrest of diffuse neuronal migration disorders. Dev Med Child Neurol 1993; 35: 331-9.

8 Byrd SE, Bohan TP, Osborn RE, Naidich TP. The CR and MR evaluation of lissencephaly. Am $\mathcal{F}$ Neurol Radiol 1988; 9: $923-7$

9 Canapicchi R, Padolecchia R, Puglioli M, Collavoli $P$, Marcella F, Valleriani AM. Heterotopic grey matter. Neuroradiological aspects and clinical correlations. f Neuroradiol 1990; 17: 277-87.

10 Trounce JQ, Fagan DG, Young ID, Levene MI. Disorders of neuronal migration: sonographic features. Dev Med Child Neurol 1986; 28: 467-71.

11 Chamberlain MC, Press GA, Bejar RF. Neonatal schizencephaly: comparison of brain imaging. Pediatr Neurol 1990; 6: 382-7.

12 Pérez-Higueras A, Cabañas F. Malformaciones cerebrales congénitas In: Pérez-Higueras A, Cabañas F, eds. Neuroultrasonografia clinica. Madrid: Edicanics Normal, 1990: 107-28.

13 Couture A, Droulle P, Didier F. Les malformations cérébrales. In: Couture A, Veyrac C, Baud C, eds. Echographie cérébrale du foetus au nouveau né. Montellier: Sauramps Médicall, 1994: 267-370.

14 Motte J, Gomes H, Morville P, Cymbalista M. Sonographic diagnosis of lissencephaly. Pediatr Radiol 1987; 17: 362-4.

15 Di Pietro MA, Brody BA, Kuban K, Cole FS. Schizencephaly: rare cerebral malformation demonstrated by sonography. Am F Neurol Radiol 1984; 5: 196-8.

16 Fariello G, Malena S, Lucigrai G, Tomà P. Hemimegalencephaly: early sonographic pattern. Pediatr Radiol 1993; 23: 151-2.

17 Barkovich AJ, Gressens P, Evrard P. Formation, maturation and disorders of brain neocortex Am $\mathcal{F}$ Neurol Radiol 1992; 13: 423-46.

18 Sarnat HB. Disturbances of late neuronal migrations in the perinatal period. Am $\mathcal{F}$ Dis Child 1987; 141: 969-80.

19 Zimmerman RA, Bilaniuk LT, Grossman RI. Computed tomography in migratory disorders brain development. Neuroradiology 1983; 25: 257-63.

20 Barkovich AJ, Kjos BO. Gray matter heterotopias: MR characteristics and correlation with developmental and neurologic manifestations. Radiology 1992; 182: 493-9.

21 Couture A, Veyrac C, Baud N, Leboucq N, Montoya F. New imaging of cerebral ischaemic lesions high frequency

22 Eken P, Jansen GH, Groenendaal F, Rademaker KJ, de Vries LS. Intracranial lesions in the fullterm infant with hypoxic ischaemic encephalopathy: Ultrasound and autopsy correlation. Neuropediatrics 1994; 25: 301-7.

23 Murphy NP, Rennie J, Cooke RW. Cranial ultrasound assessment of gestational age in low birthweight infants. Arch Dis Child 1989; 64: 569-72.

24 Cabañas F, Pellicer A, Morales C, García-Alix A, Stiris T, Quero J. New pattern of hyperechogenicity in thalamus and basal ganglia studied by color Doppler flow imaging. Pediatr Neurol 1994; 10: 109-16.

25 Barkovich AJ, Norman D. Anomalies of the corpus callosum: correlation with further anomalies of the brain. $A m \mathcal{J}$ Radiol 1988; 151: 171-9. 